\title{
Aging, research and families
}

\author{
Tony Hope Editorial Associate, Journal of Medical Ethics
}

Problems in the health care of elderly people are the focus of an international collaboration amongst a wide variety of journal editors throughout the world. The fournal of Medical Ethics is pleased to participate in this collaboration in publishing, in this issue, the paper on consent in geriatric research by Olde Rikkert and colleagues. ${ }^{1}$

Ethical issues arise frequently in the health care of the elderly. They arise, for example, in relation to: the treatment of people with impaired competence, treatment decisions near the end of life, advance directives, consent for research, and balancing patients' interests with those of carers.

My own clinical specialty is old age psychiatry. One of the justified complaints in our assessments of people with dementia is that we test patients' abilities and competence more in the manner of an entrance examination than a kindly assessment. We focus more on the weaknesses which people have than their strengths. The first question which we are inclined to ask, with regard, for example, to consent is whether the patient is competent. An alternative approach is to ask: how can we involve this person effectively in decisions about her health care? Olde Rikkert and colleagues have taken this approach with regard to consent for research. They describe a "step-wise" procedure: subjects first gave consent for a try-out week in which they took part in the research. At the end of the week they were asked whether they gave consent to the research continuing. Tests of understanding of some of the key issues were carried out before the try-out period. The authors found that research experience improved both the capacity to understand the research and to give consent, for both demented and depressed subjects.

This general approach of finding ways in which frail elderly patients can take part in decisions has more general application. For example in the case of advance directives, an approach which focuses on helping people to complete advance directives may prove more valuable than one which characterises people as competent or incompetent.

Another ethical issue which arises in the care of the elderly and which has received too little attention is the balancing of the interests of patients with those of their families.

Consider $\mathrm{Mr} \mathrm{A}$, aged 70, who is suffering from both depression and early dementia. His wife says she has had enough and wants him to be taken into a home. The professionals' assessment is that his best interests are served by his remaining at home with his wife - for she looks after him quite well. Are a spouse's wishes and interests to be considered in their own right or only as instrumental to the patient's best interests?

One approach to the question of how to resolve such conflicts is to give preference to the interests of the patient. This could be called the "dyadic approach". According to this view a doctor's overriding duty is to the patient. In a situation of conflict between the interests of the patient and the interests of others, the doctor should do whatever is best for the patient.

The dyadic view is predicated on the assumption that patients need to be protected from outside malign interference - in this case from the malign intentions of families. Nelson and Nelson, in their important book on families and medical ethics, ${ }^{2}$ point out that families are an important source of health care. In the setting of chronic illness, families are probably the major sources of caring and support. In this setting, doctors' approaches to families need to be a lot more subtle than the dyadic approach would suggest.

There are three arguments against this "dyadic view". First, that we already allow the interests of others to trump the interests or wishes of our patients in some situations. The most obvious example is over the issue of confidentiality. Here is what the General Medical Council (GMC) says about informing the spouse (or other sexual partner) of a patient's infection with HIV.

"Therefore, when a person is found to be infected in this way, the doctor must discuss with the patient the question of informing a spouse or other sexual partner. The GMC believes that most such patients will agree to disclosure in these circumstances, but where such consent is withheld the doctor may consider it a duty to seek to ensure that any sexual partner is informed, in order to safeguard such persons from infection." 3

Furthermore, the law sees issues of medical confidentiality as essentially a balance of public interests. Whilst it recognises that there is considerable public interest in doctors maintaining the confidentiality of their patients, when the public interest is better 
served by breaching confidentiality then it is lawful to breach (indeed it may be unlawful not to breach). The interests of the patient can be outweighed by these other interests.

This first argument is not specifically about relatives or carers. Families, however, are special. One reason why they are special is that they are major providers of care. Because of this family members have a right for their interests to be considered relevant, just as professionals' interests are taken into account in deciding the level of care offered. Health professionals could offer more "in the best interests of the patient", for example if staff were to work even harder than they already do. But we would not consider it right to expect staff to work all the time for the good of their patients. Ruining the home life of a National Health Service (NHS) employee for the sake of her patients is not the right thing to demand or expect. In the same way it would not seem right to expect a level of care which takes only the interests of the patient into account and not also the interests of the family. The doctor must try to find a reasonable balance between the interests of the patient and the interests of the carers, whether they be family or professional.

The third argument is that the family's interests and the patient's interests are not readily separable. Consider Mrs B who is 90 years old, has poor hearing and walks with difficulty. Her memory has started to deteriorate. She now lives with her daughter. Over the last few months she has become increasingly depressed. She now spends all her time in bed. She says that she would like to die. The conditions in which she is living are rather squalid. The room is dirty. She does not go to the toilet but gets out of bed and puts her excreta in a pot which then remains in the room. Some months ago Mrs B told the psychiatrist that she was determined to pass on the money she had saved during her life to her daughter. She didn't want her money being spent on care in an old people's home.

In such a case one could argue that the best interests of Mrs B would be served, in the long term, if she were looked after in an old person's home. This case could be seen as representing a conflict between what is in the daughter's best interests (to inherit as much as possible) and what is in Mrs B's bestT interests (to go into a home). But it is not so clear: what is in Mrs B's best interests. If Mrs B were? able to express her view she might claim that her best interests were served by considering the best? interests of her daughter.

It is not only professionals who face dilemmas $\frac{\overline{\frac{\sigma}{n}}}{\mathrm{n}}$ Insufficient attention has been paid to the ethical

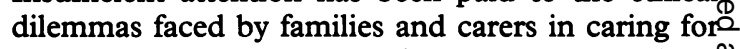
their sick relative. Julian Savulescu and I havew carried out some interviews with the relatives of people with dementia about what they see as theethical dilemmas which they have had to face. Onew carer described a question of deceit which had exer cised him greatly. The patient slept badly and was up at night interrupting the carer's much needed sleep. : The doctor prescribed sleeping pills. The patienter would agree to take a vitamin tablet but not an sleeping pill. Should the patient be told the pill is a vitamin tablet? The carer felt just as acutely as would? a professional, the competing arguments for andagainst such deception. A professional might view? such a situation as a conflict between what is in theo interests of the patient (for example not to bed deceived) and the carer (to have a night undisturbed by the patient). But the relative too felt this confligt.e

The health care of elderly people raises a wiage range of important ethical issues for professiona families, and, no doubt, for patients themselves. Such issues are of both clinical importance ando theoretical interest.

\section{Acknowledgement}

I would like to thank $\mathrm{Dr}$ Jane Pearce for helpfur discussions.

\section{References}

1 Olde Rikkert MGM, van den Bercken JHL, ten Have HAMJ, Hoefnagels WHL. Experienced consent in geriatric research. Fournal of Medical Ethics 1997; 23: 271 ३ 2 Nelson HL, Nelson JL. The patient in the family: an ethics of medicine and families. New York: Routledge, 1995.

3 General Medical Council. Duties of a doctor: HIV anto AIDS. London: GMC: 9.

\section{News and notes}

\section{A Voice for the Guinea Pig}

This conference, which will be held on Thursday October 9th, in London, will explore: the experiences of consumers who are on research ethics committees; the positive contribution to the quality of research that can be made by patients, and understanding the way the pharmaceutical industry affects the research agenda.
Speakers include: Martin Bobrow, Richard Churchill, Joe Collier, Heather Goodare, Jenny Hurst, Richard Nicholson, Naomi Pfeffer and Jean Robinson. Fee: $£ 40$.

Contact: CERES, Consumers for Ethics in Research, PO Box 1365, London N16 OBW. Tel: 01753-652781; Fax: 01753-654142. 